\title{
METHOD FOR PREDICTING THE DISSEMINATION OF HAZARDOUS SUBSTANCES IN THE SOIL DURING LONG-TERM STORAGE OF GALVANIC WASTE
}

\author{
Larisa Tretiakova \\ Department of Occupational and Civil Safety ${ }^{1}$ \\ Liudmyla Mitiuk $\bowtie$ \\ Department of Occupational and Civil Safety ${ }^{1}$ \\ luda2010703@gmail.com
}

Igor Panasiuk

Department of Technogenic Safety, Heat and Mass Transfer Processes

Kyiv National University of Technologies and Design

2 Nemyrovycha-Danchenka str., Kyiv, Ukraine, 01011

Elina Rebuel

Department of Talent and Careers

IE Business School

31 Calle de María de Molina, Madrid, Spain, 28006

${ }^{1}$ National Technical University of Ukraine «Igor Sikorsky Kyiv Polytechnic Institute»

37 Peremohy ave., Kyiv, Ukraine, 03056

$\triangle$ Corresponding author

\begin{abstract}
The problem of production waste storage in open areas of an enterprise with a galvanic shop for the production of chips and microchips has been investigated. The composition of the sludge obtained after sewage treatment of the production of the copper line was investigated.

The aim of the article is to develop a mathematical model for predicting the distribution of compounds with heavy metals in the soil during long-term storage of galvanic sludge in open areas. Modeling the process of movement of salts from the earth's surface into the lower layers of the aeration zone occurs according to the laws of molecular diffusion. The method is developed on the basis of a mathematical model that makes it possible to estimate the spread over the depth of the ground and level of soil salinity over time using initial information about soil structure and its characteristics (molecular diffusion coefficient, volume humidity), annual volumes and conditions of sludge storage in the enterprise. Restrictions are set: the presence of harmful substances on the soil surface with a concentration that exceeds the permissible level; inadmissibility of harmful substances to aquifers.

The practical use of the method made it possible to identify the main dangers during long-term storage of galvanic waste in open areas. The dynamics of soil salinity levels and the depth of penetration of heavy metals increase over twenty years of conservation has been determined, as well as the possibility of hazardous compounds entering groundwater has been assessed.

Polyvinyl chloride packaging has a maximum life span of 15 years. Waste should not be stored in packages and in closed areas for more than 10 years. According to the prediction results, it can be stated that storage in landfills of galvanic waste for more than 15 years leads to significant salinization of the soil and creates conditions for an emergency situation, which is caused by harmful substances entering the water horizons.

Recommendations for improving storage conditions are given and the need for recycling of industrial waste is substantiated.

Keywords: galvanic production, prediction, mathematical model, ingress of hazardous substances, soil salinity.
\end{abstract}

DOI: $10.21303 / 2461-4262.2022 .002231$

\section{Introduction}

At the enterprises of the military-industrial complex, mechanical engineering, electronic equipment of Ukraine a galvanic (electrochemical) method is used before drawing various coverings: chromium-plated, copper, nickel-plated, galvanized. The main advantage of this method is the ability to obtain a coating of a specified thickness - from hundreds to tens of micrometers. 
In the process of surface treatment to give them anti-corrosion and decorative properties a variety of reagents are used, which include heavy metals. The term «heavy metal» defines micro elements that can be toxic to organisms depending on their properties, chemical formation and concentration levels [1-3]. Heavy metals are harmful because of their long half-lives and ability to accumulate in different parts of the human body and the whole biosphere.

The impact of heavy metals on the environment is a well-known risk factor for cancer [4].

Heavy metal pollution of groundwater is one of the environmental problems due to its impact on human health [5]. Water supply worldwide is facing serious problems due to elevated concentrations of heavy metals $[6,7]$. Particularly dangerous are heavy metals that get into the water and are absorbed by phytoplankton, which can lead to their subsequent entry into human food [8]. Under conditions of soil contamination with heavy metals, there are problems with the adaptation of plants to them, because plants accumulate them [9]. These articles [8,9] provide information on such issues.

Galvanic production is one of the most material-intensive, in which the volume of raw materials and auxiliary materials is several times higher than the yield of finished products. Consequently, as a result of production the following waste is generated: electrolytes and etching solutions of different composition. While mixing with water during treatment, electrolytes and etching solutions enter the wastewater [10].

Consequently, as a result of production the following waste is generated: electrolytes and etching solutions of different composition. While mixing with water during treatment, electrolytes and etching solutions enter the wastewater and form additional sludge [10]. The problem posed by the storage and disposal of solid industrial waste is discussed in the article.

Dry waste (sludge) is formed during wastewater treatment. The most dangerous components of sludge are oxides of heavy metals. Depending on the technological features in the waste of various galvanic industries, heavy metals were recorded within the following limits: copper - (500..5600) mg/kg, iron - (750..1100) mg/kg, chromium $(250 \ldots 5000) \mathrm{mg} / \mathrm{kg}$,

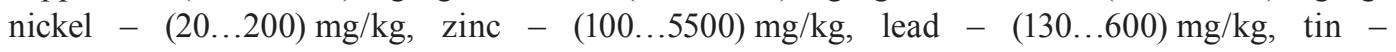
$(1200 \ldots 7600) \mathrm{mg} / \mathrm{kg}$ [11]. This leads to the annual formation of up to 12,000 tons of sludge on the territories of Ukrainian enterprises [12]. Enterprises with galvanic shops can be the main sources of toxic heavy metals in soil, water and air. Enterprises with galvanic shops can be the main sources of toxic heavy metals in soil, water and air in the region.

Due to the variety of chemical elements in the sludge and the high level of harmfulness, there was a problem of their storage, disposal and recycling. Long-term storage of galvanic waste is allowed on special sites in equipped storage facilities. However, as practice shows, artificial storage facilities have limited capacity and service life. Currently, the sludge is stored in open areas with the use of protective facing materials made of clay, polyethylene, polyvinyl chloride. Extensive flooding of territories and loose permeable soils in Ukraine complicate the choice of landfills for industrial waste and limit their area. Solid waste under the influence of precipitation, especially acid rain, turns into a liquid state. Such phenomena lead to the leakage of chemically active elements into the environment. As a result, heavy metals are contaminated not only by groundwater and surface water adjacent to storage sites, but also by groundwater horizons. Levels of soil and water pollution in the regions of Ukraine, where galvanic and painting shops are located, are significant [13].

Soil surface contamination leads to a number of problems related to soil salinity, groundwater contamination and increased water mineralization in surface waters. According to the degree of salinity, soils are divided into unsalted, slightly saline, moderately saline, strongly saline [14]. It is established that on weakly saline soils the crop yield decreases on average to $25 \%$, on moderately saline soils - up to $50 \%$, on strongly saline soils - up to $75 \%$. Soils with a salinity level exceeding $75 \%$ become practically unsuitable for plants of all species. As of 2018 , there were 4,700 million $^{2}$ of medium and heavily saline soils in Ukraine, which is $14.3 \%$ of the area of agricultural land [15].

Over time, heavy metals always move to the groundwater level [16]. Nowadays, this irresponsible attitude towards the disposal of industrial waste has caused a total pollution of $6 \%$ and a partial pollution of $25 \%$ of the explored groundwater reserves.

Predicting the development of dangerous physical-chemical processes on the surface and deep layers of soils is one of the basic requirements for environmental safety. 
Contamination of soils, surface and groundwater is assessed by various physical-chemical methods. Contamination of soils, surface and groundwater are often assessed using various physical-chemical methods.

Evaluation is based on one or a group of parameters, based on large arrays of experimental data [17-19]. Most of the methods used to determine pollution of natural water basins are quite complex. Their implementation requires large amounts of experimental data, lengthy laboratory tests, the availability of expensive special equipment, special computer software packages [20].

The above information makes it important to develop a method for predicting the levels of possible soil and groundwater pollution using mathematical models to obtain quick and informative solutions. The aim of the article is to develop a mathematical model for predicting the distribution of compounds with heavy metals in the soil during long-term storage of galvanic sludge in open areas.

The aim of the article is to develop an analytical method for predicting the distribution of compounds with heavy metals in the soil during long-term storage of galvanic sludge in open areas.

To achieve this aim, one needs to solve the following problems:

1. Analyse the experimental data on the qualitative and quantitative composition of the sludge that are formed in the galvanic shop at the manufacture of chips.

2. Develop a mathematical model of the distribution process of heavy metals, in the soil, which lead to salinity of the soil and pollution of groundwater. Based on the model, create a method for predicting the depth and concentration of contamination.

3. Check the reliability of the developed mathematical model and method, created on its basis.

4. Suggest proposals for implementation of the obtained results.

\section{Materials and Methods}

A method for predicting soil contamination in the sludge storage area is proposed. Modeling the process of movement of salts from the earth's surface into the lower layers of the aeration zone occurs according to the laws of molecular diffusion.

The research methodology is based on the use of the theory of physical-chemical hydrodynamics of porous media. The process of motion of metal salts can be described by the differential equation of motion and conservation of mass of matter for vertical mass transfer of matter [21]. The presence of sludge on the soil surface corresponds to the boundary condition of the first kind:

$$
D \frac{d^{2} C}{d X^{2}}=\Theta \frac{d C}{d T}
$$

where $D$ - molecular diffusion coefficient, $\mathrm{m}^{2} / \mathrm{s} ; C$ - salinity of the soil (rocks), $\%$; $\Theta$ - volumetric humidity, $\% ; X$ - spatial coordinate, $\mathrm{m} ; T$ - time coordinate, $\mathrm{s}$.

The analytical solution of equation (1) has the form:

$$
C_{h x}=\left(C_{s}-C_{0}\right) \operatorname{erfc}\left[\frac{1}{2} \cdot \frac{h_{x}}{\sqrt{\frac{D \cdot t}{\Theta}}}\right],
$$

where $C_{h x}$ - predicted salinity level at $h_{x}$ depth, \%; $C_{s}$ - surface salinity of the aeration zone at $\left(x_{0}, y_{0}, z_{0}\right)$ surface points at $h=0 ; C_{0}$ - the initial level of salinity at $\left(x_{0}, y_{0}, z_{0}\right)$ points on the surface of the soil before storage at $t=0 ; h_{x}$ - distance of the calculation points from the $\left(x_{0}, y_{0}, z_{0}\right)$ surface points, i.e. from the earth's surface, $\mathrm{m} ; t$ - term of prediction calculation, day; erfc - tabulated function.

The molecular diffusion coefficient $D$ characterizes the movement of metal ions as a result of thermal motion in the soil and depends on the properties of metal molecules, temperature and pressure, but is mainly determined by the concentration of the substance and humidity [16].

Volumetric moisture $\Theta$ is determined by the moisture content of the soil and depends mainly on the mechanical properties of the soil, porosity, capillarity and humus content. 


$$
\Theta=\frac{V_{w}}{V_{S}},
$$

where $V_{w}$ - the volume of water (liquid) in the soil; $V_{S}$ - the volume of the total soil, including water and gases.

For Ukraine, moisture transfer in the aeration zone at the relative constancy of natural and anthropogenic sources of water and salts, characterized by the temporal recurrence of the water-salt regime, close to the annual. There is no obvious dependence of the molecular diffusion coefficient $D$ on the season [22].

The condition for the formation of the scope of the mathematical model is the presence in the surface layer of the soil of chemically hazardous substances, the level of which exceeds the maximum allowable concentration:

$$
\rho_{i}^{d}\left(x_{0,} y_{0, z}, t\right) \geq P C_{i},
$$

where $\rho^{d}$ - concentration of the dangerous substance; $x_{0}, y_{0}, z_{0}$-initial coordinates of the source of pollution; $P C$ - permissible concentration; $i$ - chemically dangerous compound that has reached its limit (permissible concentration).

Given the spread of the danger of chemical hazardous compounds entering the water, an additional boundary condition (5) is obtained:

$$
h \leq q\left(C_{x}, t\right) \leq H,
$$

where $h$ - depth of penetration of chemically hazardous compounds into the soil; $q\left(C_{x}, t\right)$ - an indicator that further determines the nature of the spread of danger and is a reflection of the sources of danger; $H$ is the depth of the aquifer within the territory of possible distribution.

The authors performed experimental studies of the process of sludge accumulation on the territory of the enterprise during the operation of «copper etching» lines at the manufacture of chips. The research was carried out on the territory of the enterprise for the production of electronic equipment in the Cherkasy region of Ukraine.

Copper is widely used in the manufacture of chips (microchips, printed circuit boards) due to its high electrical conductivity. The process of «copper etching» is used to create and fix images on the surfaces of chips and printed circuit boards. Treatment of individual parts is parallel to the use of large amounts of water and, accordingly, the formation of waste. Spent technological solutions of chemical and electrochemical degreasing, as well as alkaline wastewater after cascade washing enter acid effluents. The spent electrolyte of the copper line is partially directed to regeneration and the regenerated solution is reused in the technological process.

Technological processes in electroplating shops lead to the formation of liquid waste with metals in the process of etching and sludge - during disposal. The enterprise has been operating for 48 years. The average production capacity is up to $2,500 \mathrm{~m}^{2}$ of chips per month. With a productivity of the digestion line of $14 \mathrm{~m}^{2} / \mathrm{h}$, the amount of sludge for 8 hours of operation reaches $(100 \ldots 120) \mathrm{kg}$. Up to $2,500 \mathrm{~kg}$ is accumulated in one shift during one month and up to $5,000 \mathrm{~kg}$ during two-shift work. On the territory of the enterprise, the productivity of which ranges from 2,000 to 4,000 $\mathrm{m}^{2}$ of chips, 30 to 48 tons of waste are accumulated annually.

Analysis of sludge of chip production showed the content of a number of heavy metals: copper $(\mathrm{Cu})-(12 \ldots 16) \%$; calcium $(\mathrm{Ca})-(6 \ldots 8) \%$; iron $(\mathrm{Fe})-(8 \ldots 10) \%$, chromium $(\mathrm{Cr})$, nickel $(\mathrm{Ni})$, zinc $(\mathrm{Zn})-$ up to $2 \%$.

Previous years, the sludge was stored on the territory of the enterprise on landfills in open areas. For the last 20 years, the sludge has been stored in polyvinylchloride packaging. During storage of sludge with particle sizes $(0.1 \ldots 50) \mu \mathrm{m}$ with metal salts, the soils are salted and this leads to the corresponding negative consequences [20]. Under the influence of precipitation, metal ions, due to easy dissolution in an acidic environment, are washed away and pass into soils, surface and groundwater. The negative consequence of such spread of chemically hazardous substances is the 
contamination of the storage area at the enterprise and the probability of contamination of the surrounding areas (suburban and agricultural).

The soil cover is heterogeneous, light mechanical composition with predominance of loam and medium sand. Soils in this area have the following structure: loam - $(1.5 \ldots 1.8) \mathrm{m}$; sand - $(1.8 \ldots 2.2) \mathrm{m}$; groundwater - $(2.6 \ldots 3.0) \mathrm{m}$; clay - $(3.8 \ldots 4.5) \mathrm{m}$; then the inter-layered water begins (Fig. 1). The pores make up to 40 percent of the soil layer.

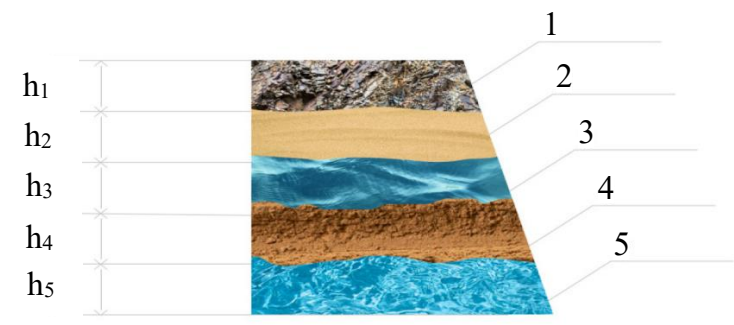

Fig. 1. Structural diagram of the soil: $1-\operatorname{loam}\left(h_{1} \leq 1.5 \ldots 1.8\right) \mathrm{m} ; 2-$ sand $\left(h_{2} \leq 0.3 \ldots 0.5\right) \mathrm{m}$; 3 - groundwater $\left(h_{3} \leq 0.8 \ldots 1.0\right) \mathrm{m} ; 4$ - clay $\left(h_{4} \leq 1.2 \ldots 1.5\right) \mathrm{m} ; 5$ - interlayer water $\left(h_{5}>1.2\right) \mathrm{m}$

Dangerous substances containing $\mathrm{Zn}$ (zinc), $\mathrm{Pb}$ (lead), $\mathrm{Cd}$ (cadmium), $\mathrm{Cu}$ (copper) have been fixed in soils and plants of Cherkasy region [23]. Numerous experimental studies show that soils are characterized by a high content of easily soluble salts, which makes it possible to classify them as excessively saline. In the soils of Cherkasy region, the total salt content varies within $(0.11 \ldots 0.41) \% .41 \%$ of soils are characterized as slightly saline, $39 \%$ - as moderately saline, $20 \%$ - as highly saline [24, 25].

According to the proposed research method, the prediction of heavy metal penetration depth and soil salinity levels is determined with the following problem statements:

1. Warehousing and storage of sludge in the open area for twenty years.

2. Warehousing of sludge and storage in packages (in polyvinyl chloride packages) in the open area for twenty years.

The following assumptions were made during the prediction: the process of metal accumulation is cumulative; the annual season of soil moisture changes is not taken into account. One year (365 days) is accepted for the settlement period. The total prediction time is 20 years.

\section{Results}

\section{1. Storage of sludge in an open area without packaging}

At the first statement of the problem the following initial indicators are accepted:

- salinity of the soil surface before storage is $C_{o}=0.15 \%$;

- movement of salts occurs only in a porous medium. According to the structure of the soil at the place of storage, the pores make up to 40 percent of the soil volume. Let's take the maximum value of $C_{s}=40 \%$ at the boundary «air - soil surface», which corresponds to a constant layer of slag at $\left(x_{0}, y_{0}, z_{0}\right)$ points on the surface;

- molecular diffusion coefficient was taken $D=1 \cdot 10^{-5} \mathrm{~m}^{2} /$ day;

- volume humidity taking into account seasonal fluctuations in the range $\Theta=0.20-0.23-0.27$;

- when predicting the depth of penetration of metal molecules, the calculation points were selected with a step of $0.1 \mathrm{~m}$ from the surface.

Prediction with qualitative and quantitative indicators is implemented using Microsoft Excel Application Software.

The calculations according to the given algorithm were performed after the first year of storage with variable values of bulk humidity $0.20-0.23-0.27$. The maximum penetration depth of heavy metals was up to $0.6 \mathrm{~m}$ (Fig. 2).

As follows from Fig. 2, seasonal changes in volumetric humidity do not significantly affect the depth of penetration of heavy metals and the level of soil salinity. Therefore, in further calculations let's take the average annual value of volumetric humidity $\Theta=0.23$. 


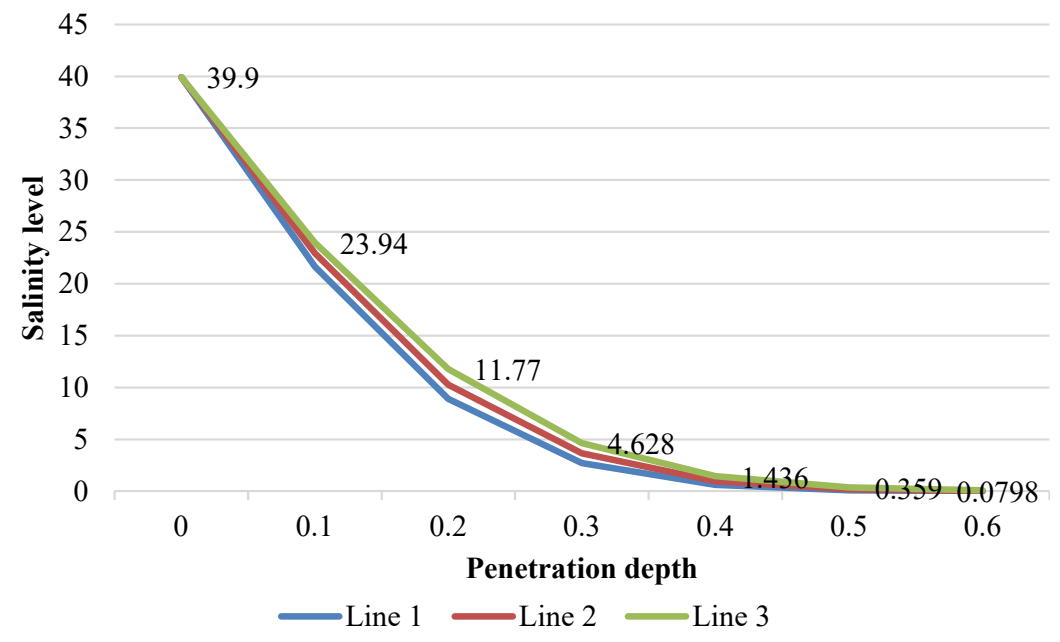

Fig. 2. Changes in soil salinity by depth after the first year of storage at different volumetric humidity values: 1 - volumetric humidity $0.20 ; 2-0.23 ; 3-0.27$

Next, the depth of penetration of heavy metals into the aeration zone for the next 20 years is predicted. Fig. 3 shows the change in the depth of salinity for the first five years, in Fig. 4 up to 20 years of storage.

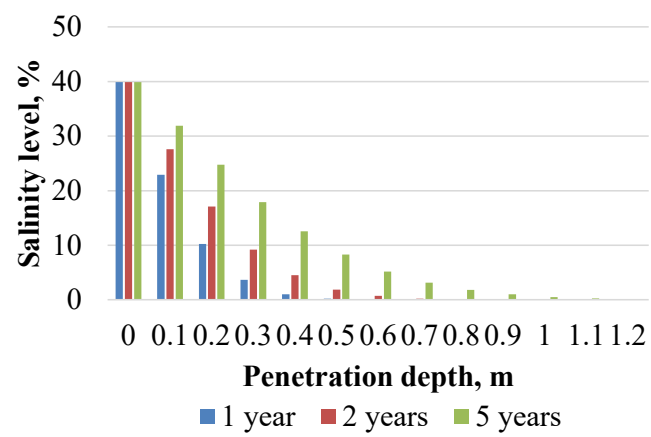

Fig. 3. Change in the level of soil salinity in depth during the first five years of storage: 1 - after the first year of storage; 2 - after the second year of storage;

3 - after the fifth year of storage

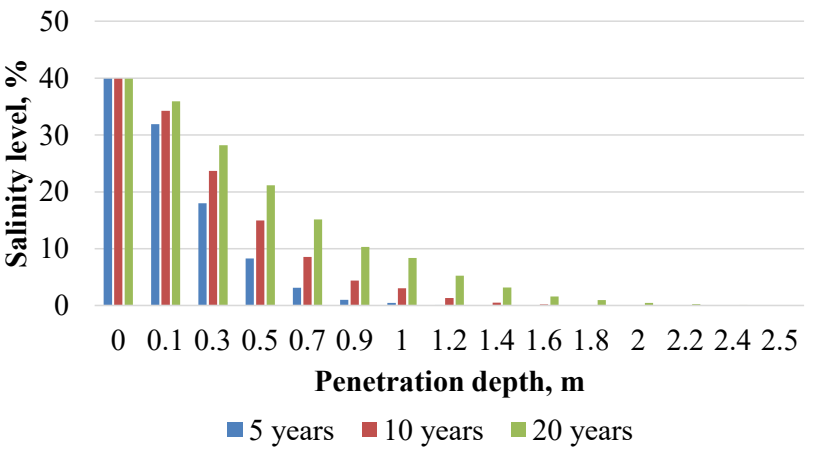

Fig. 4. Change in the level of soil salinity in depth during twenty years of storage:

1 - after the fifth storage year; 2 - after ten years of storage; 3 - after twenty years of storage

Calculations and analysis of statistically obtained data at the test site have shown that there is an annual increase in the depth of penetration of heavy metals and after $10 \ldots 12$ years there may be a threat of an emergency situation, which is due to the input of harmful substances into groundwater. 


\section{2. Storage of sludge in the open area in the package}

Predicting the depth of penetration and salinity levels for 20 years during the storage of sludge in the packaging in the open area has certain features. In the second formulation of the problem it is necessary to take into account the changes in the salinity levels of the surface during the calculation period, i.e. $\left.C_{S}\right|_{h=0} \rightarrow$ var. Storage of sludge in polyvinylchloride packaging leads to gradual contamination of the surface layer. This is due to damage to the packaging, primarily due to the destruction of the joints, which are obtained by high-frequency welding. The joints crack under the influence of mechanical loads, changes in external temperatures, ultraviolet radiation and precipitation, which results in the formation of a permanent layer of sludge in the storage areas. It should also be mentioned that the guaranteed service life of this type of packaging does not exceed 15 years.

Prediction using formula (2) is not time-limited. Analytical dependence, which describes the process of transformation and concentration of chemically hazardous compounds in soil elements depending on the storage time of the sludge [26], has the form:

$$
\frac{d C}{d t}=C_{s}\left(\rho_{i}^{d}, x_{0}, y_{0}, z, t\right) \cdot K_{1} \cdot \exp \left(K_{2} t\right)
$$

where $t$ - storage time of chemically hazardous compounds in the sludge; $K_{1}, K_{2}$ - process speed constant.

Preliminary evaluation in the laboratory of the rate of polyvinylchloride packaging destruction made it possible to determine the change in concentration of sludge on the surface over time, and to construct an analytical dependence (6) on the rate of salinity of the soil surface (Fig. 5).

$$
C_{s}=C_{0} \cdot \exp \left(K_{2} \cdot t\right)=0.15 \cdot \exp (275 \cdot t)
$$

Fig. 5 identifies the influence of precipitation significantly affects the process of destruction of packaging. It is recommended to store the packaging in open areas under a canopy (awning), which provides protection from rain, temperature variations, moisture and wind.

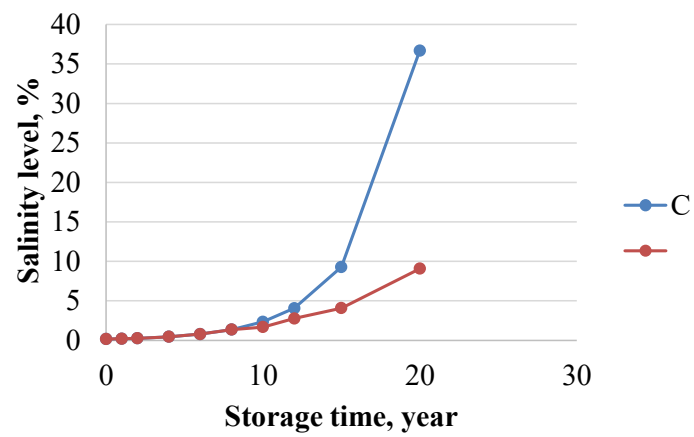

Fig. 5. Change of the $C_{s}$ surface salinity depending on the duration of storage:

1 - packaging is in the open area; 2 - packages are in a closed area

Long-term prediction of soil contamination during storage of sludge in polyvinylchloride packaging in the open area, obtained as a result of iterative calculation by the given algorithm according to formulas (2)-(7).

Fig. 6 shows the change in the depth of the salinity level for the first five years, in Fig. 7 up to 20 years of storage.

As can be seen from Fig. 4, 5, during storage of sludge in polyvinylchloride packaging, the salinity on the surface decreases compared to the first condition (open storage) and the process of penetration of heavy metals into the depth slows down. However, during the preservation of packaging in open areas, their gradual destruction occurs. This process causes in $15 \ldots 20$ years the levels of pollution similar under the conditions of open storage (Fig. 8). 


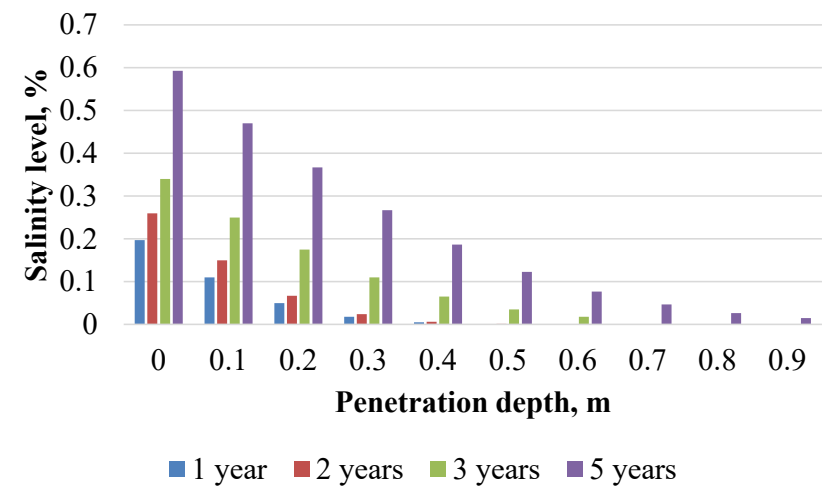

Fig. 6. The depth of penetration of heavy metals change depending on the storage duration: row 1 - for one year of storage; row 2 - for two years of storage; row 3 - for three years of storage; row 4 - for five years of storage

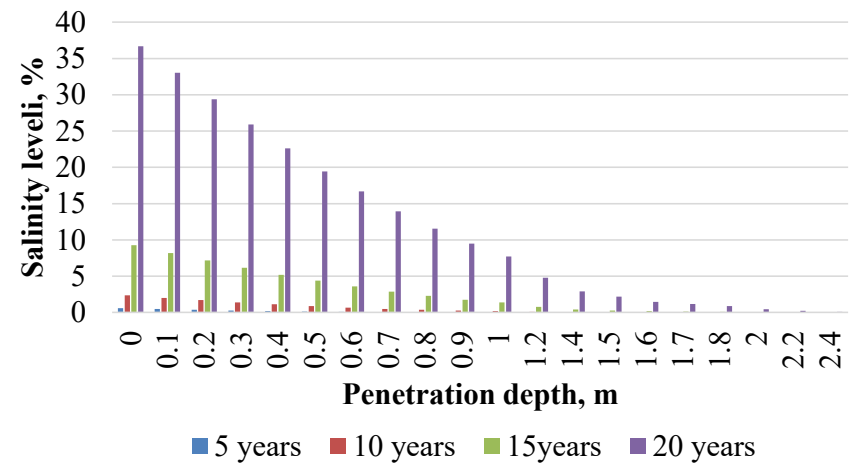

Fig. 7. The depth of penetration of heavy metals change depending on the storage duration: row 1 - five years of storage; row 2 - ten years of storage; row 3 - fifteen years of storage; row 4 - twenty years of storage

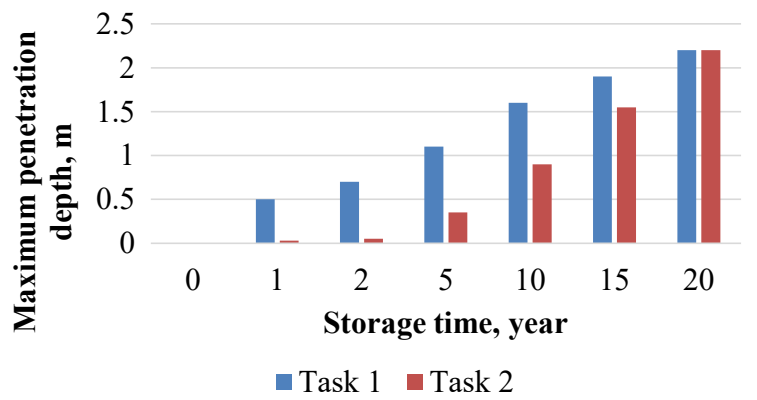

Fig. 8. Dependence of penetration depth of heavy metals into the soil on the duration of storage: 1 - storage of sludge without packaging; 2 - storage of sludge in the package in the open area

As follows from Fig. 8, when the sludge is placed on the open surface in a year, the soil $0.65 \mathrm{~m}$ thick goes into the category of poorly saline, in four years such a layer reaches a depth of 1 meter, in 15 years the depth reaches two meters, which creates conditions for groundwater contamination. The contamination process is slower when the sludge is stored in the package. However, if the service life exceeds 15 years, the process of polymer destruction packaging takes place and further storage leads to contamination of soil and groundwater.

\section{Discussion}

Analysis of literature sources have showed that the ingress of heavy metals into the soil leads to: salinization of the soil and loss of its fertility [25]; secondary contamination of plants 
that are widely used in food [4]; pollution of surface and deep layers of water horizons, which are often used as sources of drinking water [5]. Heavy metals have a negative effect on human health, increase the risk of internal diseases and cancer $[1,2]$.

Contamination of soils, surface and groundwater is assessed by various physical-chemical methods. Most of the methods used to determine pollution of natural water basins are quite complex [7, 8, 17-19]. Their implementation requires large amounts of experimental data [7], lengthy laboratory tests $[7,8,19]$, the availability of expensive special equipment [8], special computer software packages [18].

The research methodology is based on the use of the theory of physical-chemical hydrodynamics of porous media. The proposed mathematical model is presented in the form of three analytical equations (1)-(3), which with sufficient accuracy establish the dependence of the penetration of heavy metal molecules in the soil depth depending on storage time $t$ (2), soil salinity (2) and seasonal humidity fluctuations $\theta$ (3). The method can be used to assess environmental safety under these conditions: the presence of chemical hazardous substances in the surface soil that exceed the maximum permissible concentration (4); the risk of chemicals entering surface or groundwater aquifers (5).

Informativeness, ease of implementation, and the ability to assess over the long term are the main advantages of this method. The implementation of this method does not require: a large amount of experimental data compared to the methods proposed in [7, 9]; long laboratory studies, the results of which are given in [7, 8, 19]; availability of expensive special equipment [8], which most Ukrainian enterprises do not have, and special computer software packages [18].

According to the prediction results, it can be stated that storage in landfills of galvanic waste for more than 15 years leads to significant (up to $40 \%$ ) salinization of the soil (Fig. 5) and will create conditions for an emergency situation, which is caused by harmful substances entering the water horizons. Heavy metal compounds penetrate to a depth of $1.2 \mathrm{~m}$ after 10 years of storage and to $2.4 \mathrm{~m}$ after 20 years of storage. Polyvinyl chloride packaging deteriorates when exposed to sunlight and external temperature fluctuations, especially in winter. Therefore, the use of packaging to store sludge is advisable in closed storage, which makes it possible to prevent their rapid destruction.

A disadvantage of the method is the use of primary information with a high level of uncertainty. Soil structure and characteristics (diffusion porosity) can vary significantly depending on the location. The molecular diffusion coefficient $D$ depends on the properties of metal molecules, temperature and pressure, but is mainly determined by the concentration of the substance and humidity. Volume humidity $\Theta$ depends on the mechanical properties of the soil, porosity, capillarity, humus content and meteorological conditions, which have seasonal and annual variations.

The practical implementation of the proposed method has been carried out only on the work site (storage yard) of an enterprise. Obviously, it is advisable to perform similar studies in other areas with different soil structure. The characteristics that depend on the seasonal fluctuations of water and salts in the soil are subject to additional clarification.

An example of the application of a mathematical model in an individual enterprise can be recommended to prevent man-made emergencies and optimize measures to prevent their occurrence in other areas. To prevent contamination of soil and groundwater must be implemented effective methods of wastewater treatment and sludge recycling. Ukraine has a high demand for copper, which is used in the electrical, aircraft, and defense industries. The required copper raw material can be obtained by galvanic wastewater treatment. In the current economic and technological conditions, it is advisable to use sludge as a secondary raw material.

\section{Conclusions}

The method for predicting the spread of hazardous substances in soils has been proposed. The method provides an analytical assessment of soil contamination over the long term. As initial data for the model the following information was used: soil structure and its characteristics (molecular diffusion coefficient, volume humidity); annual volumes of sludge and concentration of hazardous substances; conditions of sludge storage on the territory of the enterprise. 
According to the results of calculations it is established:

- during the placement and storage of sludge in the open area annually the level of salinity and depth of penetration of heavy metals into the soil $(0.5 \mathrm{~m}$ in the first year, $1.2 \mathrm{~m}$ for five years, $1.6 \mathrm{~m}$ for ten years to $2.4 \mathrm{~m}$ after twenty years of storage) increase. This process creates conditions for the pollution of water horizons, which in this area are located at a depth (2.6...3.0) m;

- during the use of packaging made of polyvinyl chloride to save the sludge, the contamination process is slower $(0.1 \mathrm{~m}$ in the first year, $0.5 \mathrm{~m}$ for five years, $1.1 \mathrm{~m}$ for ten years);

- after ten years of storage, the process of polymer destruction packing takes place and further storage leads to faster soil and groundwater contamination $(1.7 \mathrm{~m}$ for fifteen years, $2.3 \mathrm{~m}$ for twenty years).

Calculation results were verified at the chip production facility, quantitative indicators of sludge accumulation during the operation of «copper etching» lines were determined.

The method will be useful for predicting the risk of soil and water pollution emergencies.

\section{Acknowledgments}

The authors' team is grateful to the administration of the enterprise «Skif» and its director S. Bychenko for help in verifying the calculation results. The authors would like to express sincere gratitude for advices in the preparation of this paper to prof. A. Nester.

\section{References}

[1] Elumalai, V., Brindha, K., Lakshmanan, E. (2017). Human Exposure Risk Assessment Due to Heavy Metals in Groundwater by Pollution Index and Multivariate Statistical Methods: A Case Study from South Africa. Water, 9 (4), 234. doi: https://doi.org/ 10.3390/w9040234

[2] Ab Razak, N. H., Praveena, S. M., Aris, A. Z., Hashim, Z. (2015). Drinking water studies: A review on heavy metal, application of biomarker and health risk assessment (a special focus in Malaysia). Journal of Epidemiology and Global Health, 5 (4), 297. doi: https://doi.org/10.1016/j.jegh.2015.04.003

[3] Adamu, C. I., Nganje, T. N., Edet, A. (2015). Heavy metal contamination and health risk assessment associated with abandoned barite mines in Cross River State, southeastern Nigeria. Environmental Nanotechnology, Monitoring \& Management, 3, 10-21. doi: https://doi.org/10.1016/j.enmm.2014.11.001

[4] Orellana, E., Bastos, M. C., Cuadrado, W., Zárate, R., Sarapura, V., Yallico, L. et. al. (2020). Heavy Metals in Native Potato and Health Risk Assessment in Highland Andean Zones of Junín, Peru. Journal of Environmental Protection, 11 (11), $921-937$. doi: https://doi.org/10.4236/jep.2020.1111058

[5] Shrestha, S. M., Rijal, K., Pokhrel, M. R. (2016). Assessment of Heavy Metals in Deep Groundwater Resources of the Kathmandu Valley, Nepal. Journal of Environmental Protection, 07 (04), 516-531. doi: https://doi.org/10.4236/jep.2016.74047

[6] Hashim, M. A., Mukhopadhyay, S., Sahu, J. N., Sengupta, B. (2011). Remediation technologies for heavy metal contaminated groundwater. Journal of Environmental Management, 92 (10), 2355-2388. doi: https://doi.org/10.1016/j.jenvman.2011.06.009

[7] Lemos, D. H. R., Camargo, C. A. C. M., Camargo, M. A. F., Landgraf, M. D. (2019). Evaluation on the Concentration of Heavy Metals in Surface Waters in the Municipality of Pratápolis-MG. OALib, 06 (05), 1-13. doi: https://doi.org/10.4236/oalib.1105427

[8] Zarazúa, G., Girón-Romero, K., Tejeda, S., León, C. C.-D., Ávila-Pérez, P. (2014). Total Reflection X-Ray Fluorescence Analysis of Toxic Metals in Fish Tissues. American Journal of Analytical Chemistry, 05 (12), 805-811. doi: https://doi.org/10.4236/ ajac.2014.512089

[9] Hu, Z., Li, J., Wang, H., Ye, Z., Wang, X., Li, Y. et. al. (2019). Soil Contamination with Heavy Metals and Its Impact on Food Security in China. Journal of Geoscience and Environment Protection, 07 (05), 168-183. doi: https://doi.org/10.4236/ gep.2019.75015

[10] Bondareva, L. P., Chesnokov, A. I., Zagorulko, E. A. (2018). Separation of cations of heavy metalsfrom concentrated galvanic drains. Proceedings of the Voronezh State University of Engineering Technologies, 80 (1), 223-227. doi: https://doi.org/ 10.20914/2310-1202-2018-1-223-227

[11] Bondarenko, I. V., Anischenko, L. Y., Rudyk, Y. I. (2017). Substantiation for enhancement of environmental safety of waste management systems through forecasting efficiency of specialized equipment. Bulletin of Lviv State University of Life Safety, 2, (16), 119-128. Available at: https://media.neliti.com/media/publications/313853-substantiation-for-enhancement-ofenviro-29ca51d0.pdf

[12] Rybiy, V. V., Bredihin, V. M., Chervonij, I. F, Maniak, M. O. (2013). Recycling of precious metals. Eastern-European Journal of Enterprise Technologies, 3 (5 (63)), 35-38. Available at: http://journals.uran.ua/eejet/article/view/14509/12320 
[13] Baliuk, S., Drozd, O. (2019). Assessment of production eco-system services of the salted and solonetzic soils of South of Ukraine. Visnyk Agrarnoi Nauky, 97 (1), 60-67. doi: https://doi.org/10.31073/agrovisnyk201901-09

[14] Balyuk, S. A., Drozd, E. N., Naidenova, O. E., Nosonenko, A. A. (2019). Assessment of Provisioning Ecosystem Services of Irrigated Salt-Affected Soils in Ukraine. Eurasian Soil Science, 52 (4), 436-447. doi: https://doi.org/10.1134/s1064229319040045

[15] Natsionalna dopovid pro stan navkolyshnoho pryrodnoho seredovyshcha v Ukraini u 2019 rotsi. Available at: https://mepr. gov.ua/news/37844.html

[16] Shevchenko, O. L., Bublias, V. M., Kolomiets, S. S. (2016). Osnovy perenesennia volohy v zoni aeratsiyi. Kyiv, 263. Available at: https://www.nas.gov.ua/UA/Book/Pages/default.aspx?BookID=0000009841

[17] Vouvé, F., Buscail, R., Aubert, D., Labadie, P., Chevreuil, M., Canal, C. et. al. (2013). Bages-Sigean and Canet-St Nazaire lagoons (France): physico-chemical characteristics and contaminant concentrations $(\mathrm{Cu}, \mathrm{Cd}, \mathrm{PCBs}$ and PBDEs) as environmental quality of water and sediment. Environmental Science and Pollution Research, 21 (4), 3005-3020. doi: https://doi.org/ 10.1007/s11356-013-2229-1

[18] Deng, Y., Ni, F., Yao, Z. (2012). The Monte Carlo-Based Uncertainty Health Risk Assessment Associated with Rural Drinking Water Quality. Journal of Water Resource and Protection, 04 (09), 772-778. doi: https://doi.org/10.4236/jwarp.2012.49088

[19] Loboichenko, V. M., Vasyukov, A. E., Tishakova, T. S. (2017). Investigations of Mineralization of Water Bodies on the Example of River Waters of Ukraine. Asian Journal of Water, Environment and Pollution, 14 (4), 37-41. doi: https://doi.org/ 10.3233/ajw-170035

[20] Milman, B. (2008). Introduction to chemical identification. Saint Petersburg: VVM, 180. Available at: https://www.twirpx. com/file/1896302/

[21] Nester, A., Tretyakova, L., Mitiuk, L., Prakhovnik, N., Husev, A. (2020). Remediation of Soil Containing Sludge Generated by Printed Circuit Board Production and Electroplating. Environmental Research, Engineering and Management, 76 (4), 68-75. doi: https://doi.org/10.5755/j01.erem.76.4.25460

[22] Dreval, Y., Loboichenko, V., Malko, A., Morozov, A., Zaika, S., Kis, V. (2020). The Problem of Comprehensive Analysis of Organic Agriculture as a Factor of Environmental Safety. Environmental and Climate Technologies, 24 (1), 58-71. doi: https:// doi.org/10.2478/rtuect-2020-0004

[23] Kornelyuk, N. M., Khomenko, O. M. (2018). Bioaccumulation of heavy metals by the urban trees around Cherkassy thermal power plant. Ukrainian Journal of Ecology, 8 (1), 953-960. doi: https://doi.org/10.15421/2018_298

[24] Zaiets, R., Kovaliov, A., Buzhyn, O., Dzylai, O. (2016). Assessment of air pollution level in Cherkassy. Transactions of Kremenchuk Mykhailo Ostrohradskyi National university, 2 (97), 109-114. Available at: http://www.kdu.edu.ua/PUBL/ statti/109_2_2016_1.pdf

[25] Myslyuk, O., Khomenko, O., Yehorova, O., Kachai, V. (2019). Assessment of urban soils salinification in cherkasy. Transactions of Kremenchuk Mykhailo Ostrohradskyi National University, 5, 52-57. doi: https://doi.org/10.30929/1995-0519.2019.5.52-57

[26] Loboichenko, V., Strelec, V. (2018). The natural waters and aqueous solutions express-identification as element of determination of possible emergency situation. Water and Energy International, 61 (9), 43-50. Available at: http://repositsc.nuczu. edu.ua/handle/123456789/10156

How to cite: Tretiakova, L., Mitiuk, L., Panasiuk, I., Rebuel, E. (2022). Method for predicting the dissemination of hazardous substances in the soil during long-term storage of galvanic waste. EUREKA: Physics and Engineering, 1, 12-22. doi: https://doi.org/ 10.21303/2461-4262.2022.002231 